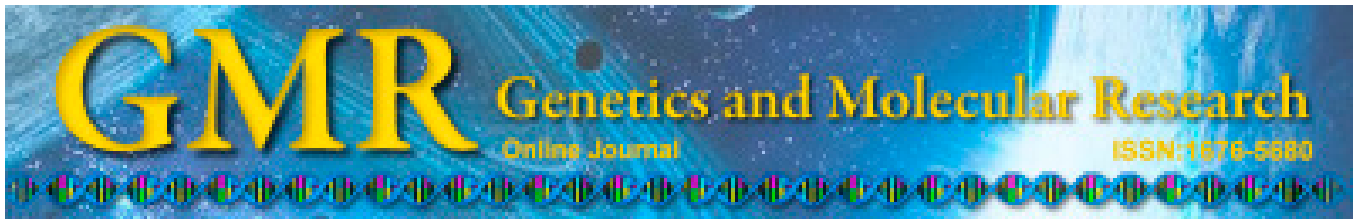

\title{
Molecular cloning and characterization of a novel Y-box gene from Sepiella maindroni
}

H.P. Si, C.L.Wang, Y.Y. Zhang, C.K. Mu, P.P. Zhan, R.H. Li and W.W. Song

Key Laboratory of the Ministry of Education for Applied Marine Biotechnology, Ningbo University, Ningbo, China

Corresponding author: W.W. Song

E-mail: songweiwei@nbu.edu.cn

Genet. Mol. Res. 14 (2): 5750-5762 (2015)

Received July 8, 2014

Accepted March 5, 2015

Published May 29, 2015

DOI http://dx.doi.org/10.4238/2015.May.29.7

ABSTRACT. Y-box proteins are a family of highly conserved nucleic acid binding proteins that interact with genome and transcription product to modulate the transcriptional and translational processes. In the present study, a complete mRNA of Y-box binding protein (designated SmYB) was obtained from Sepiella maindroni by amplification of flanking sequences. The full size of SmYB cDNA was $1502 \mathrm{bp}$, including 99 bp at the $5^{\prime}$ untranslated region (UTR), a 3' UTR of 821 bp with a poly (A) tail, and an open reading frame of $582 \mathrm{bp}$, encoding a polypeptide of 193 amino acids with the predicted molecular weight of $16.48 \mathrm{kDa}$. The conserved cold-shock domain and two known RNA binding motifs identified in SmYB strongly suggested that SmYB was a new member of Y-box proteins. Quantitative real-time PCR was performed to examine the expression of SmYB mRNA in various tissues, embryos, and its temporal expression in liver after cold shock. The mRNA transcript of SmYB was detected in all examined tissues, with the highest expression level in testis and ovary. SmYB was abundant in early developmental stages of $S$. maindroni embryos but diminished in the late post-embryonic development. In addition, cold-shock treatment upregulated the transcription of SmYB mRNA in liver. These results 
demonstrated that SmYB is involved in embryonic development of $S$. maindroni and its tolerance to acute low temperatures.

Key words: Sepiella maindroni (SmYB); Y-box; Gene cloning; mRNA expression; Embryonic development; Cold shock

\section{INTRODUCTION}

The Y-box proteins are a family of regulatory proteins characterized by the presence of a highly conserved nucleic acid-binding domain, which shows substantial similarity to bacterial cold shock proteins (Makino et al., 1996; Kohno et al., 2003). Y-box proteins were reported to perform a wide variety of cellular functions, including transcriptional activation, chromatin modification, translational repression, DNA repair, and RNA Packaging (Faustino and Cooper, 2003). Y-box proteins can interact with both DNA and RNA to modulate the transcriptional and translational processes (Wolffe, 1994; Ladomery and Sommerville, 1995; Matsumoto and Wolffe, 1998). In addition, the member of this family is also an oncogenic transcription/translation factor that is overexpressed in a number of cancer types including prostate (Giménez-Bonafé et al., 2004), bone (Oda et al., 1998), colon (Shibao et al., 1999), muscle (Oda et al., 2003), and most recently breast cancer (Stratford et al., 2007). Shiota et al. (2014) reported that Y-box binding protein-1 signaling improves cellular sensitivity to taxane in prostate cancer.

In cytoplasm, Y-box proteins are essential for messenger ribonucleoprotein (mRNP) particles in which mRNA is stored and may act as a mRNA chaperone or a translation repressor (Evdokimova et al., 2001; Bader and Vogt, 2005; Lu et al., 2006). Y-box proteins have also been reported to be transported into the nucleus from the cytoplasm to modulate gene expression in response to physiological and environmental stress factors (Koike et al., 1997).

Members of the Y-box protein family have been characterized in numerous phylogenetically diverse organisms (Graumann and Marahiel, 1998). Prokaryotic cold-shock proteins, consisting entirely of a cold shock domain (CSD), bind selectively to single- or doublestranded DNA (Graumann and Marahiel, 1996; Yamanaka et al., 1998). Eukaryotic Y-box proteins have an additional carboxyl-terminal tail, which facilitates nucleic acids binding and is involved in protein-protein interaction (Wolffe et al., 1992; Bouvet et al., 1995; Nambiar et al., 1998). The CSD of Eukaryota, containing two RNA binding motifs, RNP-1 and RNP2 (Burd and Dreyfuss, 1994), shares substantial similarity (55\%) to bacterial CSD proteins (Landsman, 1992). This domain in bacteria is involved in single-stranded nucleic acids binding (Schindelin et al., 1994). The C-terminal following CSD shows less homology among these proteins. In fact, there are distinctly different types of nucleic acids binding modes in the $\mathrm{C}$-terminal domain. Tail domains of invertebrates have in common an enrichment in arginine and glycine, while the vertebrate Y-box proteins contain multiple independent nucleic acidbinding domains (Matsumoto and Wolffe, 1998).

Based on the broad nucleic acid-binding properties of Y-box proteins, some patterns regarding their expression and function are beginning to emerge. For example, the Y-box protein in oocytes of Xenopus laevis prevents translation of maternal mRNA until development is initiated (Sommerville and Ladomery, 1996; Thieringer et al., 1997). The Y-box protein in mouse is highly expressed in spermatocytes (Didier et al., 1988) and developing embryos (Lu et al., 2005). In addition, there is a subset of Y-box proteins, which are highly expressed in 
actively proliferating adult tissues such as the colorectal epithelial glands and regenerating liver tissue after hepatectomy (Grant and Deeley, 1993; Ito et al., 1994; Shibao et al., 1999). Many of these proteins are reported to be in connection with growth related processes (Ladomery and Sommerville, 1995). Several Y-box proteins in bacteria are induced upon temperature downshift, and they maintain mRNA molecules in a single stranded conformation to facilitate translation at low temperature (Jiang et al., 1997). Although many eukaryotic Y-box proteins have been cloned, the question of cold inducibility of these proteins has not been addressed yet.

Sepiella maindroni is an important and valuable fishery species in China. Their life and activity are influenced by low temperatures because of their poor ability to withstand freezing (Li et al., 2010), and massive deaths by frostbite had frequently occurred after a cold snap in cultured $S$. maindroni populations. Since Y-box proteins carry out multiple functions, such as transcriptional activation, DNA repair or RNA Packaging (Faustino and Cooper, 2003; Kohno et al., 2003), studying the Y-box protein gene from S. maindroni will help elucidate the molecular mechanisms of embryonic development and tolerance to acute low temperature, which in turn will contribute to the cultivation of fine strains in farming. Dias et al. (2014) found that SmYB1 functions in the turnover, transport, and/or stabilization of RNA molecules during post-transcriptional gene regulation.

The main objectives of the present study were: 1) to clone the full-length cDNA of Y-box protein gene from $S$. maindroni; 2) to investigate tissue distribution of the SmYB transcript; 3) to describe the expression pattern of the $\operatorname{Sm} Y B$ gene during embryonic development; 4) to examine the temporal response of SmYB mRNA to acute low temperature at the mRNA level.

\section{MATERIAL AND METHODS}

\section{Animals, embryos, acute low temperature challenge, and liver collection}

S. maindroni larvae, averaging $4 \mathrm{~cm}$ in length, were collected in Ningbo, China, and acclimated at $22^{\circ} \pm 2^{\circ} \mathrm{C}$ for one week before processing. One hundred and eighty cuttlefish were employed for the cold treatment experiment. The cuttlefish were randomly divided into nine groups and each group contained 20 individuals. Six groups were exposed to $14^{\circ}$ or $18^{\circ} \mathrm{C}$, and three control groups were maintained at $22^{\circ} \mathrm{C}$, which was normal temperature of the aquaculture water. After the treatment, three individuals were randomly sampled at $0,0.5,2,6,12$, 24, 48, and $72 \mathrm{~h}$. The liver was collected and preserved in RNAlater (TaKaRa, Tokyo, Japan) for RNA extraction. Muscle, ink sac, liver, pancreas, ovary, testis, stomach, and gill from $S$. maindroni adults were collected to determine tissue distribution of SmYB transcript. Total RNA was extracted using RNAiso Plus (TaKaRa) according to the manufacturer protocol.

Fertilized eggs were collected and acclimated at $20^{\circ} \pm 1^{\circ} \mathrm{C}$. The embryonic development of $S$. maindroni was divided into 12 stages (unpublished data), and to facilitate the research, they were combined into 5 major developmental stages: I) the zygote stage; II) the pre-embryonic stage, which occurs over a very short period of time, including cleavage stage, blastula, and gastrula; III) the organogenesis stage, when the main parts of a bodily structure or organs, like wrist, eye, heart, pigment, etc., are formed; IV) the morphological integrity stage, which corresponds to the ongoing further improvement of bodily structure, with a yolk sac still present; V) the pre-hatching stage when the yolk sac disappears, while the larvae are preparing for hatching. Embryos were collected at these five stages and used for RNA extraction. 


\section{cDNA library construction}

Total RNA from the embryos of S. maindroni was extracted with TRIzol reagent (Invitrogen, Carlsbad, CA, USA) at the stage V. First- and double-stranded cDNAs were synthesized according to the protocol for the SMART cDNA Library Construction Kit (Clontech Laboratories, Inc., Mountain View, CA, USA). Subsequently, approximately $2 \mu \mathrm{L}$ of first strand cDNA sample was amplified using UPM primer. The first four peak fractions containing cDNA ( $>500 \mathrm{bp}$ ) were pooled together using column chromatography with a CHROMA SPIN-400 medium (Clontech). The cDNA was ligated to $\lambda$ TriplEx2 vector (1:1.5), and the ligation was packaged with a Gigapack III Gold Packaging extract (Stratagene, La Jolla, CA, USA). Recombination efficiency was identified by blue/white screening in E. coli XL1-Blue. Colony PCR was used to confirm the size of inserted fragments in the library.

\section{Sequencing and analysis}

cDNA clones were selected randomly from the cDNA library and single-pass sequenced using random T3 primer on an ABI 3730 Genetic Analyzer (Applied Biosystems, Foster City, CA, USA). A large-scale EST sequencing project for S. maindroni was initiated to identify and functionally annotate as many unique transcripts as possible. BLAST search was used to compare processed cDNA sequences against ESTs and genes available in the GenBank database (http://www.ncbi.nlm.nih.gov/blast). A total of 860 unigenes were assembled from 1018 ESTs, which were obtained in the present study. Interestingly, one EST (GenBank No. GT618028; Contig356; length: 538 bp) was the mirror of a Y-box factor in Aplysia californica (P41824) in BLASTx analysis.

\section{Cloning the full-length cDNA of SmYB}

Amplification of flanking sequences was carried out by a 5'- and 3'-Full RACE kit (TaKa$\mathrm{Ra}$ ) to obtain the complete sequence of EST (GT618028). Operating steps were referenced following the manuals of these kits. Purified sequences were cloned into pMD-18T vector (TaKaRa) and transformed into Escherichia coli Top10F competent cells. Finally, M13-47 and RV-M universal primers (Table 1) were used to screen for three positive recombinants to be used for sequencing.

\section{3'-RACE}

The 3'-RACE was performed with a 3'-Full RACE CoreSet Ver. 2.0 (TaKaRa) following manufacturer instructions. The first-round PCR consisted of initial denaturation at $94^{\circ} \mathrm{C}$ for $4 \mathrm{~min}$, followed by 32 cycles at $94^{\circ} \mathrm{C}$ for $45 \mathrm{~s}, 52^{\circ} \mathrm{C}$ for $45 \mathrm{~s}$, and $72^{\circ} \mathrm{C}$ for $90 \mathrm{~s}$, and a final extension for $7 \mathrm{~min}$ at $72^{\circ} \mathrm{C}$. The second PCR with nested primers consisted of $4 \mathrm{~min}$ at $94^{\circ} \mathrm{C}$, followed by 32 cycles at $94^{\circ} \mathrm{C}$ for $45 \mathrm{~s}, 51^{\circ} \mathrm{C}$ for $45 \mathrm{~s}$, and $72^{\circ} \mathrm{C}$ for $90 \mathrm{~s}$, and a final extension for another $7 \mathrm{~min}$ at $72^{\circ} \mathrm{C}$.

\section{5'-RACE}

The 5'-RACE was carried out with a 5'full RACE kit (TaKaRa Code: D315) following manufacturer instructions. Total RNA was extracted from the second flower. mRNA was 
dephosphorylated and the mRNA cap structure was removed. A 5'-RACE adaptor was ligated to the decapped mRNA with a 5'-full RACE kit (TaKaRa) and the first-stranded cDNA was synthesized by reverse transcription. The first-round PCR protocol consisted of initial denaturation at $94^{\circ} \mathrm{C}$ for $4 \mathrm{~min}$, followed by 32 cycles at $94^{\circ} \mathrm{C}$ for $45 \mathrm{~s}, 58.7^{\circ} \mathrm{C}$ for $45 \mathrm{~s}$, and $72^{\circ} \mathrm{C}$ for $60 \mathrm{~s}$, and a final extension of $7 \mathrm{~min}$ at $72^{\circ} \mathrm{C}$. The second-round PCR with nested primers consisted of $4 \mathrm{~min}$ at $94^{\circ} \mathrm{C}$, followed by 32 cycles at $94^{\circ} \mathrm{C}$ for $45 \mathrm{~s}, 59^{\circ} \mathrm{C}$ for $45 \mathrm{~s}$, and $72^{\circ} \mathrm{C}$ for $60 \mathrm{~s}$, and a final extension of $7 \mathrm{~min}$ at $72^{\circ} \mathrm{C}$.

Table 1. Oligonucleotide primers used in the experiment.

\begin{tabular}{lll}
\hline Primer & Sequence $\left(5^{\prime}-3^{\prime}\right)$ & Sequence information \\
\hline P1 (reverse) & TC ACCATCTCCAACACTCCT & SmYB specific primer \\
P2 (forward) & GCTCAAGATGAGGGTTCAGAAT & SmYB specific primer \\
P3 (forward) & CATGGCTACATGCTGACAGCCTA & Universal primer \\
P4 (reverse) & TACCGTCGTTCCACTAGTGATTT & Universal primer \\
P5 (forward) & GAGGGTGAAGTAGAGACTAC & Real-time SmYB primer \\
P6 (reverse) & ACTCCACCTTCTCACCATCT & Real-time SmYB primer \\
P7 (forward) & GACTCCTACGTAGGAGACGA & Real-time actin primer \\
P8 (reverse) & CGTTGAAGGTCTCGAACATGA & Real-time actin primer \\
M13-47 & CGCCAGGGTTTTCCCAGTCACGAC & Vector primer \\
RV-M & GAGCGGATAACAATTTCACACAGG & Vector primer \\
\hline
\end{tabular}

\section{Sequence analysis, multiple sequences alignment, and phylogenetic analysis}

Sequence similarity of nucleotide and protein sequences was examined with BLAST (http://www.ncbi.nlm.nih.gov/Blast.cgi). Amino acid sequences were deduced by Expert Protein Analysis System (Artimo et al., 2012; http://www.expasy.org). The binding motives within proteins were identified by simple Modular Architecture Research Tool (SMART) (Letunic et al., 2014; http://smart.embl-heidelberg.de/). Signal peptides of amino sequences were predicted by SignalP 3.0 (Bendtsen et al., 2004; http://www.cbs.dtu.dk/services/SignalP/). Neighbor-joining method used to reconstruct phylogenetic network and multiple sequence alignment between amino acid sequences of $\mathrm{SmYb}$ and its homologs in other species were carried out with MEGA 5.0 (Tamura et al., 2011; http://www.megasoftware.net/).

\section{Quantitative analysis of SmYB mRNA expression}

Real-time PCRs were performed using an ABI 7300 (Applied Biosystems). The PCR was carried out in a final volume of $20 \mu \mathrm{L}$ with $12.5 \mu \mathrm{L}$ SYBR Green Real-time PCR Master Mix (Toyobo, Osaka, Japan), $4.5 \mu \mathrm{L}$ water, $0.5 \mu \mathrm{L}$ of each primer (P5 and P6 for SmYB and $\mathrm{P} 7$ and P8 for $\beta$-actin, see Table 1), and $2 \mu \mathrm{L}$ cDNA. The reactions were performed at $95^{\circ} \mathrm{C}$ for $3 \mathrm{~s}$, followed by 40 cycles at $95^{\circ} \mathrm{C}$ for $5 \mathrm{~s}, 56^{\circ} \mathrm{C}$ for $5 \mathrm{~s}$, and $72^{\circ} \mathrm{C}$ for $20 \mathrm{~s}$, and a final extension at $72^{\circ} \mathrm{C}$ for $1 \mathrm{~min}$. Each reaction was repeated three times, and the same reaction mixtures without cDNA were used as negative controls. The relative amount of target mRNA was calculated using the $2^{-\Delta \Delta C t}$ method. Significant differences were analyzed using the SPSS software (IBM Corp., Armonk, NY, USA). 


\section{RESULTS}

\section{Identification and analysis of SmYB cDNA}

The complete cDNA sequence of SmYB was obtained by overlapping the sequence of EST (GenBank No. GT618028) with the amplified fragments. The complete mRNA of this gene was deposited in the GenBank (No. HQ179101). The full-length mRNA sequence of SmYB is $1502 \mathrm{bp}$, including 682-bp code region (open reading frame, ORF), which starts at the position 100 and extends to the position 681, indicating that the 193-amino acid protein is $16.48 \mathrm{kDa}$ with theoretical isoelectric point predicted at 10.06 . The polyadenylation signal, AATAAA, was found at position 1289, followed by a poly-A tail in the 3'-terminal region. The deduced amino acid sequence of SmYB is shown in Figure 1. The analysis with SMART revealed that this protein sequence carried a cold-shock domain (from Ser31 to Pro99) and two putative RNA binding motives (i.e., RNP-1 and RNP-2) presented at the N-terminus of SmYB. However, no signal peptide region was found at the N-terminus. The C-terminal tail of the protein is extremely basic with high arginine $(26 \%)$ and glycine $(16 \%)$ content.

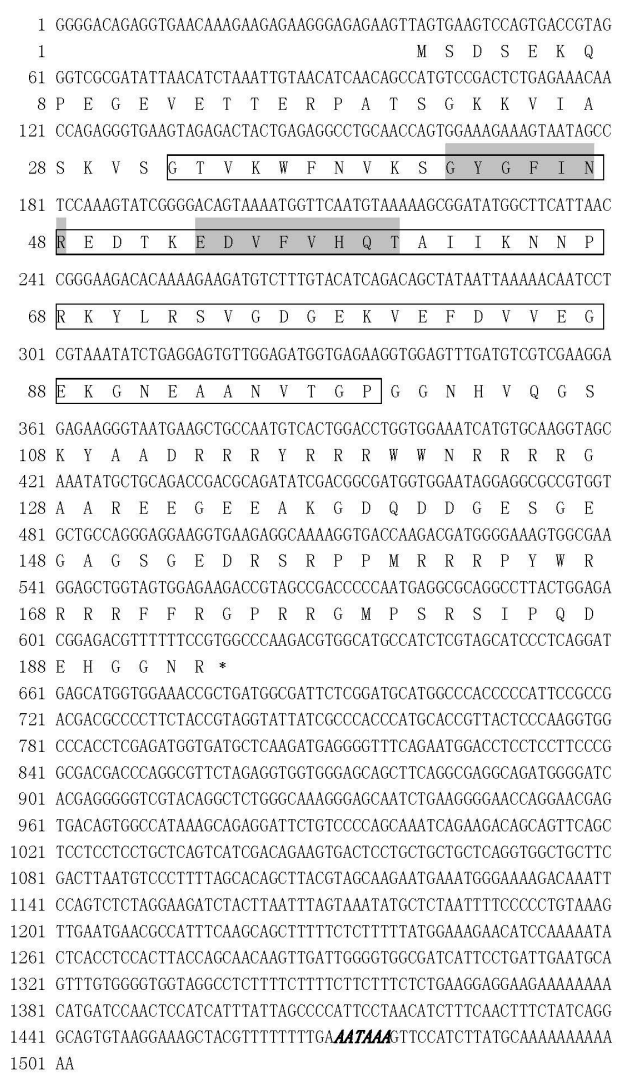

Figure 1. Nucleotide sequence of the $S m Y B$ gene with its deduced amino acid sequence. Asterisk indicates the stop codon. Polyadenylation signal is in bold and italicized. The cold-shock domain is boxed. RNP-1 (GYGFINR) and RNP-2 (EDVFVHQT) RNA binding motifs presented in shadow bold letters. 


\section{Multiple sequences alignment and phylogenetic analysis}

BLASTp and phylogenetic analysis showed that the SmYB sequence was highly homologous with other Y-box proteins: 73\% homology with Lethenteron japonicum (ACF33226), $68 \%$ homology with A. californica (P41824), and 58\% homology with Saccoglossus kowalevskii (XP_002732435). In addition, multiple alignments revealed that the CSD as well as the two RNA-binding motifs (RNP-1 and RNP-2) were highly conserved within all Y-box proteins analyzed (Figure 2). Phylogenetic tree of the Y-box proteins, constructed using MEGA 4.0 software, resolved there groups including vertebrates, invertebrates, and prokaryotes, and the sequence of SmYB was resolved within the invertebrate branch (Figure 3).

\section{Distribution of SmYB mRNA}

The qPCR was conducted to analyze expression of SmYB in various tissues, such as muscle, ink sac, liver, pancreas, ovary, testis, stomach, and gill. The results showed that SmYB expression was significantly greater in testis and ovary. Its expression in pancreas, liver, and gill was comparatively at medium levels, whereas weak signal of the SmYB transcript was detected in stomach, muscle, and ink sac. The relative expression levels in tissues of testis, ovary, liver, and pancreas were 582.43-, 102.31-, 47.57-, and 49.90-fold, respectively, of that in the ink sac with a significant difference $(\mathrm{P}<0.05)$. The expression levels of SmYB in gill, stomach, and muscle were slightly higher than in ink sac, but the difference was not significant $(\mathrm{P}>0.05)$ (Figure 4).

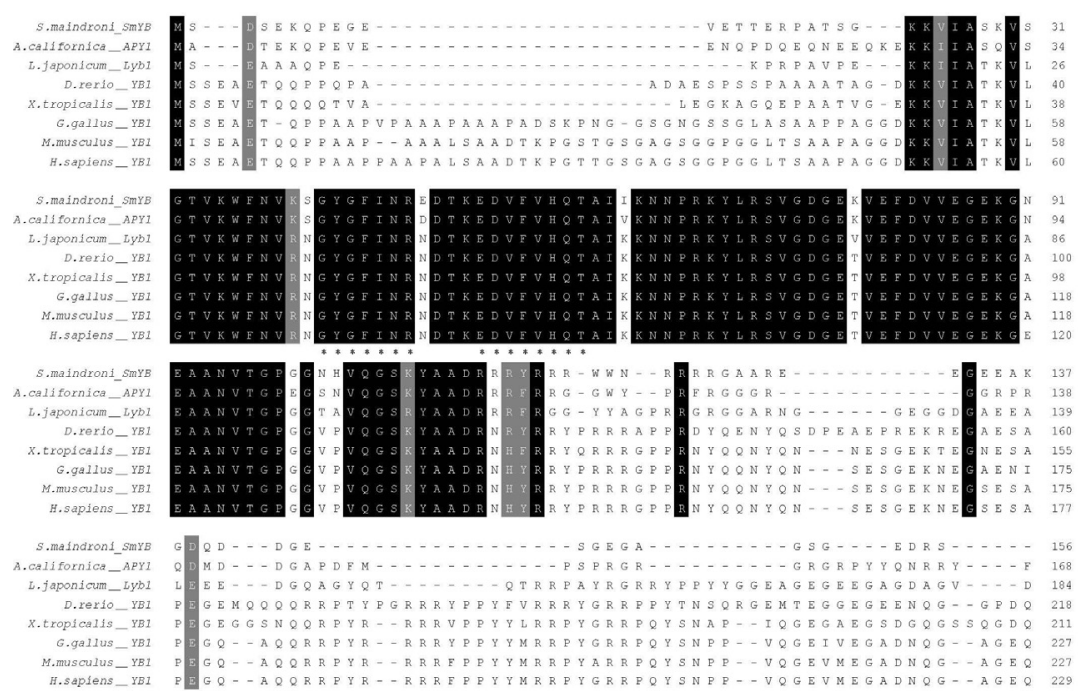

Figure 2. Multiple sequence alignment of the deduced SmYB amino acid sequence and other members of Y-box binding protein family deposited in the GenBank. The black shadow region indicates positions with the same amino acid residue. Gaps are indicated by dashes. RNP-1 (GYGFINR) and RNP-2 (EDVFVHQT) RNA binding motifs are marked by asterisks below the sequence. Abbreviations are as follows: P41824 (Aplysia californica APY1), ACF33226 (Lethenteron japonicum_Lyb1), AAH50156 (Danio rerio_YB1), NP_001016677 (Xenopus tropicalis_YB1), NP_989745 (Gallus gallus_YB1), AAH49977 (Mus musculus_YB1), and AAA61308 (Homo sapiens_Ȳ 1 1). 


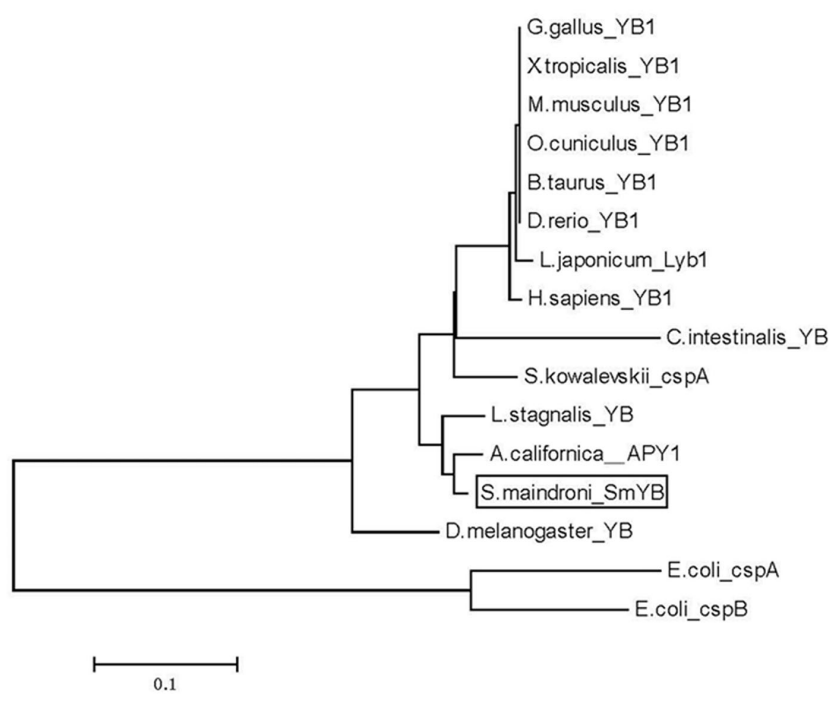

Figure 3. Consensus neighbor-joining tree based on sequences of Y-box proteins from different animals. Protein sequences used for phylogenetic analysis are as follows: P41824 (Aplysia californica_APY1), NP_001016677 (Xenopus tropicalis_YB1), ACF33226 (Lethenteron japonicum_Lyb1), AAT97092 (Lymnaea stagnalis_YB), NP_777240 (Bos taurus_YB1), NP_001076254 (Oryctolagus cuniculus_YB1), AAH49977 (Mus musculus_ȲB1), AAĀ61308 (Homo sapiens_YB1), AAB94634 (Drosophila melanogaster_YB), NP_989745 (Gallus gallus YB1), AAH50156 (Danio rerio_YB1), NP_001072039 (Ciona intestinalis_YB), XP_002732435 (Saccoglossus kowalevskii_cspA), AAA23617 (Escherichia coli_cspA), and YP_003502592 (E. coli_cspB).

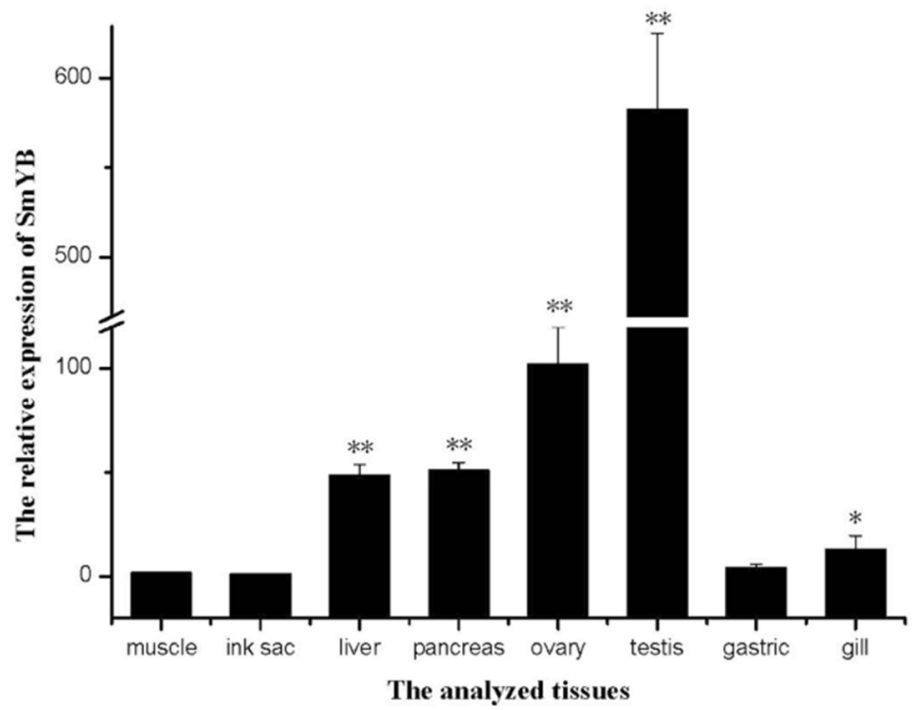

Figure 4. Tissue distribution of the SmYB transcript measured by SYBR Green Real time-PCR. The tissues, including muscle, ink sac, liver, pancreas, ovary, testis, stomach, and gill were collected from three individual cuttlefish. Vertical bars represent the mean $\pm \mathrm{SD}(\mathrm{N}=3)$. $*$ and $* *$ indicate significant differences across calibrator (ink sac) at $\mathrm{P}<0.05$ and $\mathrm{P}<0.05$, respectively. 


\section{Expression pattern of the $S m Y B$ gene during embryonic development}

The mRNA expression level of $\operatorname{SmYB}$ gene in the embryos was detected by qPCR. The $S m Y B$ gene transcript was detected in all stages of development that were tested. The expression level decreased steadily during development. SmYB mRNA was detectable until the pre-hatching stage. The highest expression was found in the zygote stage, at about 13.26-fold of that in the pre-hatching stage $(\mathrm{P}<0.05)$ (Figure 5).

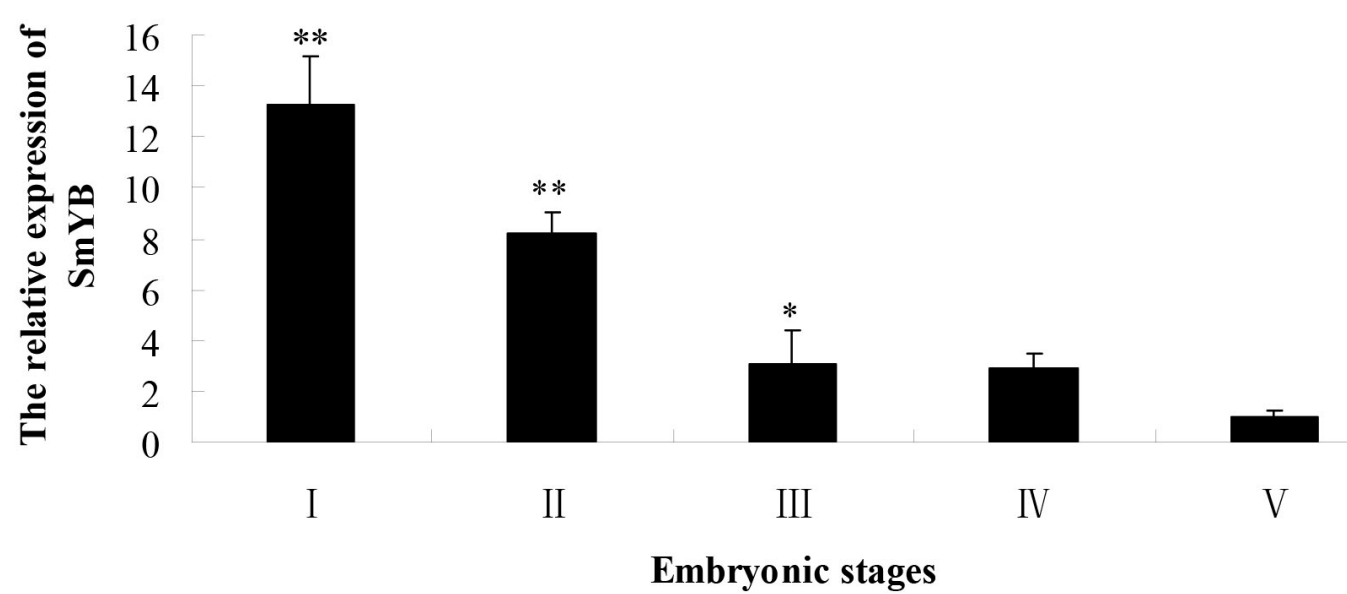

Figure 5. Expression of the SmYB mRNA at different embryonic stages measured by SYBR Green Real timePCR. $\beta$-actin gene was used as an internal control to calibrate the cDNA template for all samples. * and **indicate significant differences at $\mathrm{P}<0.05$ and $\mathrm{P}<0.05$, respectively.

\section{Expression of SmYB mRNA in liver after cold shock}

To characterize the response of the $\operatorname{Sm} Y B$ gene to external temperature stimulus, S. maindroni larvae were exposed to $14^{\circ}$ or $18^{\circ} \mathrm{C}$ for $0.5,2,6,12,24,48$, and $72 \mathrm{~h}$, while the control groups were maintained at $22^{\circ} \mathrm{C}$. The expression of SmYB was analyzed by qPCR with $\beta$-actin as internal control. As shown in Figure 6, SmYB expression in the two experimental groups showed the same trends. In the first few hours after the cold shock, the SmYB mRNA expression was slightly downregulated, but it was not significantly different from that in the control group $(\mathrm{P}>0.05)$. As time progressed, the expression of SmYB mRNA increased significantly; the expression peak at $14^{\circ} \mathrm{C}$ and $48 \mathrm{~h}$ was 3.82 -fold higher than that observed in the control group at the same time period $(\mathrm{P}<0.05)$, while the peak at $18^{\circ} \mathrm{C}$ and $12 \mathrm{~h}$ was 3.33 -fold higher than that in the control group $(\mathrm{P}<0.05)$. The SmYB mRNA expression of the two groups both reverted to the original levels in the last few hours of the experiment (Figure 6). 


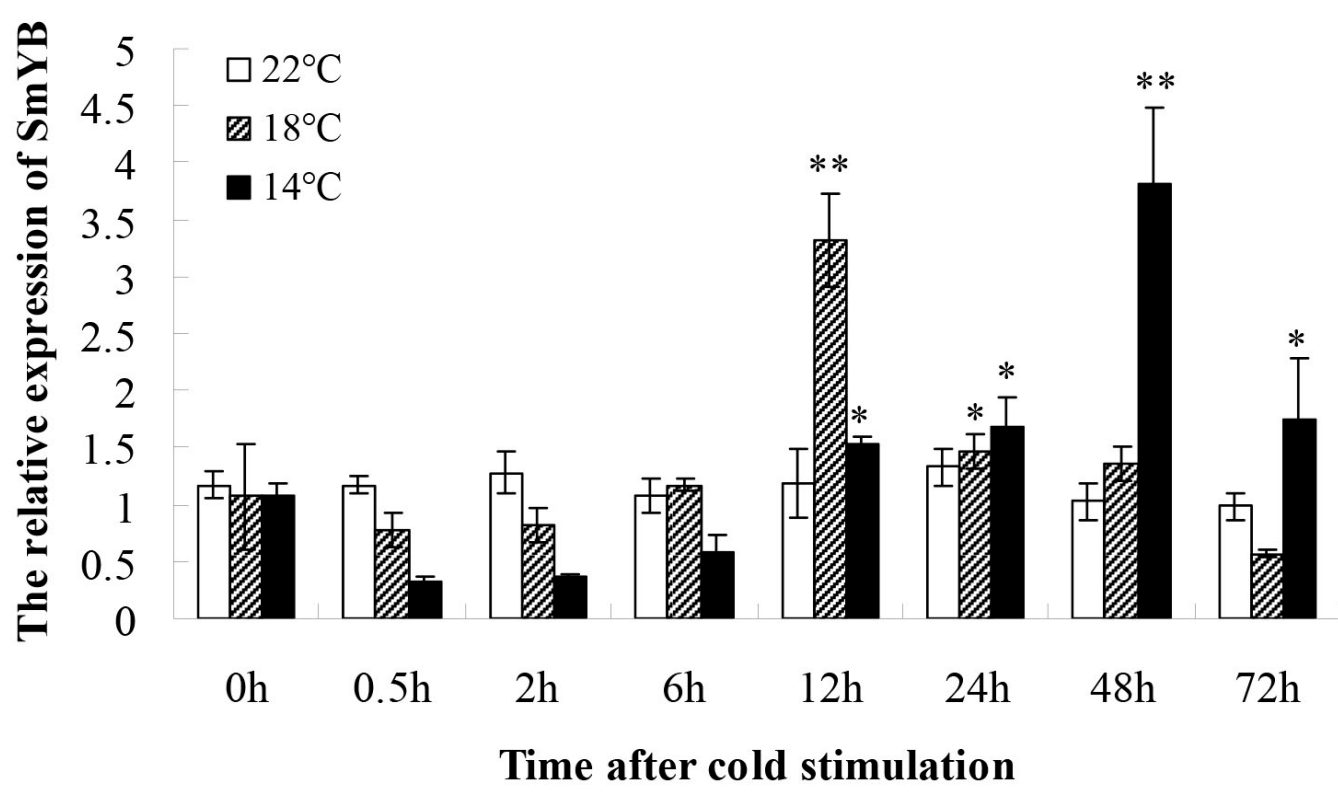

Figure 6. Temporal expression of the Y-box gene transcript in liver during the cold shock. Sepiella maindroni larvae were incubated at $18^{\circ}$ or $14^{\circ} \mathrm{C}$ for $0,0.5,2,6,12,24,48$, and $72 \mathrm{~h}$. Control groups were maintained at 22 ${ }^{\circ} \mathrm{C}$. Each bar represents the mean value from three determinations with standard error.

\section{DISCUSSION}

Y-box proteins are widely expressed in organisms from bacteria to humans and play vital roles in multiple biological processes (Evdokimova et al., 2001; Lu et al., 2006). In this study, a full-length cDNA encoding a member of the Y-box protein family (SmYB) was identified from S. maindroni, $1502 \mathrm{bp}$ in length. BLASTx analysis revealed that SmYB is homologous to Y-box proteins from other animals ( $73 \%$ to L. japonicum, $68 \%$ to A. californica, and $58 \%$ to $S$. kowalevskii). The conserved CSD and two known RNA binding motifs identified in SmYB classified it as a member of eukaryotic Y-box proteins (Graumann and Marahiel, 1998). However, the Cterminal tail of SmYB has a high frequency of arginine and glycine, which is characteristic of invertebrate Y-box proteins (Matsumoto and Wolffe, 1998), and phylogenetic analysis clustered SmYB together with invertebrates and distant to other organisms. Therefore, we conclude that SmYB belongs to the invertebrate subgroup of the Y-box protein family.

Y-box proteins regulate the utilization of maternal and paternal stores of mRNA by translational machinery in non-dividing germ cells (Matsumoto and Wolffe, 1998). For example, the mouse homolog MSY1 has been demonstrated to be implicated in masking of mRNA transcripts in spermatocytes (Tafuri et al., 1993). In Xenopus oocytes, FRGY2 binds to maternal mRNAs and masks them from translation (Yu et al., 2001, 2004). In the present study, SmYB was constitutively expressed in all examined tissues, with the highest expression level in testis and ovary. The results indicated that SmYB is involved in the development of S. maindroni germ cells.

Y-box protein expression is closely associated with cell proliferation (Wolffe et al., 
1992). For instance, Y-box protein is abundantly expressed in actively proliferating adult tissues such as colorectal epithelial glands, regenerating liver tissue that develops after hepatectomy (Grant and Deeley, 1993; Ito et al., 1994; Shibao et al., 1999), and YB-1 from mouse protects cells from senescence during periods of proliferative stress ( $\mathrm{Lu}$ et al., 2006). The mRNA for SmYB is expressed throughout the embryogenesis, and its amount declines gradually from stage I to stage $\mathrm{V}$. The highest expression of SmYB was found in the zygote stage, which was 13.26-fold of that in the pre-hatching stage $(\mathrm{P}<0.05)$. Early embryonic period can be considered to be the time of substantial proliferative stress because the early-stage embryogenesis involves massive cellular proliferation that occurs over a very short period of time ( $\mathrm{Lu}$ et al., 2006). High expression of SmYB in early-stage embryos showed that SmYB is important for cellular stress responses and plays an important role in embryonic development.

Cold shock is the most primitive form of stress that organisms can be exposed to, from bacteria to plants and animals (Kohno et al., 2003). Three of the bacterial Y-box protein homologs were induced upon temperature downshift, and they maintained mRNA molecules in a single stranded conformation at low temperature to facilitate translation (Lee et al., 1994; Jiang et al., 1997). Whether eukaryotic Y-box binding proteins are involved in the cold-shock response or not is still uncertain. In the present study, we tested this by using liver from $S$. maindroni larvae, because liver is the major metabolizing organ (Rigato et al., 2007) and has an endogenous SmYB expression. During the first few hours after the cold shock treatment, the SmYB mRNA expression was slightly down-regulated, but no significant difference between the experimental and control groups was observed, indicating that the cold shock response leads to temporary cessation of the liver growth and reduction in SmYB expression in protein synthesis in S. maindroni larvae. The expression of SmYB mRNA increased significantly with the time, which is explained by the immune rejection of body or the basic defense system. The result was similar to the expression pattern of cold-shock proteins in E. coli treated with cold shock (Jiang et al., 1997). By contrast, the expression level increased earlier in the samples exposed to $18^{\circ} \mathrm{C}$ than in the samples exposed to $14^{\circ} \mathrm{C}$. This indicates that the damage to the cells was milder due to slightly lower temperature, and the organisms could facilitate quicker their recovery and growth. We can conclude that SmYB is a cold-shock inducible gene, and it displays a protective role against cold shock.

In conclusion, a novel Y-box protein gene $(\operatorname{SmYB})$ was cloned from $S$. maindroni. SmYB was constitutively expressed in muscle tissue and tissues of the ink sac, liver, pancreas, ovary, testis, stomach, and gill, and it is highly expressed in testis and ovary. The SmYB mRNA is abundant in the early stages of the development of $S$. maindroni embryos but diminishes in the late post-embryonic development. Cold-shock treatment up-regulates the transcription of SmYB mRNA in liver. The results of this study indicate that $\operatorname{SmYB}$ is a specific gene involved in cellular growth and protection by providing resistance to cold stimulus.

\section{ACKNOWLEDGMENTS}

The authors are grateful to all the laboratory members for continuous technical advice and helpful discussion. Research supported by the National Natural Science Foundation of China (\#41176124 and \#41206114), Natural Science Foundation of Zhejiang (\#Z3110482), Innovative Research Team in University (\#PCSIRT) (\#IRT0734), Major Program for Science and Technology Planning Project of Zhejiang Province (\#2009C03017-3, \#2007C12061), and the K. C. Wong Magana Fund provided by Ningbo University. 


\section{REFERENCES}

Artimo P, Jonnalagedda M, Arnold K, Baratin D, et al. (2012). ExPASy: SIB bioinformatics resource portal. Nucleic Acids Res. 40: W597-W603.

Bader AG and Vogt PK (2005). Inhibition of protein synthesis by Y box-binding protein 1 blocks oncogenic cell transformation. Mol. Cell Biol. 25: 2095-2106.

Bendtsen JD, Nielsen H, von Heijne G and Brunak S (2004). Improved prediction of signal peptides: SignalP 3.0.J. Mol. Biol. 340: 783-795.

Bouvet P, Matsumoto K and Wolffe AP (1995). Sequence-specific RNA recognition by the Xenopus Y-box proteins. An essential role for the cold shock domain. J. Biol. Chem. 270: 28297-28303.

Burd CG and Dreyfuss G (1994). Conserved structures and diversity of functions of RNA-binding proteins. Science 265: 615-621.

Dias SR, Boroni M, Rocha EA, Dias TL, et al. (2014) Evaluation of the Schistosoma mansoni Y-box-binding protein (SMYB1) potential as a vaccine candidate against schistosomiasis. Front. Genet. 5: 174.

Didier DK, Schiffenbauer J, Woulfe SL, Zacheis M, et al. (1988). Characterization of the cDNA encoding a protein binding to the major histocompatibility complex class II Y box. Proc. Natl. Acad. Sci. U. S. A. 85: 7322-7326.

Evdokimova V, Ruzanov P, Imataka H, Rught B, et al. (2001). The major mRNA-associated protein YB-1 is a potent 5' cap-dependent mRNA stabilizer. EMBO J. 20: 5491-5502.

Faustino NA and Cooper TA (2003). Pre-mRNA splicing and human disease. Genes Dev. 17: 419-437.

Giménez-Bonafé P, Fedoruk MN, Whitmore TG, Akbari M, et al. (2004) YB-1 is upregulated during prostate cancer tumor progression and increases P-glycoprotein activity. Prostate 15; 59: 337-49.

Grant CE and Deeley RG (1993). Cloning and characterization of chicken YB-1: regulation of expression in the liver. Mol. Cell Biol. 13: 4186-4196.

Graumann P and Marahiel MA (1996). A case of convergent evolution of nucleic acid binding modules. Bioessays 18: 309-315.

Graumann PL and Marahiel MA (1998). A superfamily of proteins that contain the cold-shock domain. Trends Biochem. Sci. 23: 286-290.

Ito K, Tsutsumi K, Kuzumaki K, Gomez PF, et al. (1994). A novel growth-inducible gene that encodes a protein with a conserved cold-shock domain. Nucleic Acids Res. 22: 2036-2041.

Jiang W, Hou Y and Inouye M (1997). CspA, the major cold-shock protein of Escherichia coli, is an RNA chaperone. $J$. Biol. Chem. 272: 196-202.

Kohno K, Izumi H, Uchiumi T, Ashizuka M, et al. (2003). The pleiotropic functions of the Y-box-binding protein, YB-1. Bioessays 25: 691-698.

Koike K, Uchiumi T, Ohga T, Toh S, et al. (1997). Nuclear translocation of the Y-box binding protein by ultraviolet irradiation. FEBS Lett. 417: 390-394.

Ladomery M and Sommerville J (1995). A role for Y-box proteins in cell proliferation. Bioessays 17: 9-11.

Landsman D (1992). RNP-1, an RNA-binding motif is conserved in the DNA-binding cold shock domain. Nucleic Acids Res. 20: 2861-2864.

Lee SJ, Xie A, Jiang W, Etchegaray JP, et al. (1994). Family of the major cold-shock protein, CspA (CS7.4), of Escherichia coli, whose members show a high sequence similarity with the eukaryotic Y-box binding proteins. Mol. Microbiol. 11: 833-839.

Letunic I, Doerks T and Bork P (2014). SMART: recent updates, new developments and status in 2015. Nucleic Acids Res. Pii: gku949. doi:10.1093/nar/gku949.

Li YZ, Pan H, Xu J, Fan XW, et al. (2010). Characterization of metal removal by os sepiae of Sepiella maindroni Rochebrune from aqueous solutions. J. Hazard. Mater. 179: 266-275.

Lu ZH, Books JT and Ley TJ (2005). YB-1 is important for late-stage embryonic development, optimal cellular stress responses, and the prevention of premature senescence. Mol. Cell. Biol. 25: 4625-4637.

Lu ZH, Books JT and Ley TJ (2006). Cold shock domain family members YB-1 and MSY4 share essential functions during murine embryogenesis. Mol. Cell. Biol. 26: 8410-8417.

Makino Y, Ohga T, Toh S, Koike K, et al. (1996). Structural and functional analysis of the human Y-box binding protein (YB-1) gene promoter. Nucleic Acids Res. 24: 1873-1878.

Matsumoto K and Wolffe AP (1998). Gene regulation by Y-box proteins: coupling control of transcription and translation. Trends Cell Biol. 8: 318-323.

Nambiar A, Kandala JC, Svoboda J and Guntaka RV (1998). Cloning of a novel Y-box homology protein (chkYB-1HP) cDNA lacking the cold-shock domain. Biochim. Biophys. Acta. 1395: 1-6. 
Oda Y, Miura H, Tsuneyoshi M and Iwamoto Y (1998). Giant cell tumor of bone: oncological and functional results of long-term follow-up. Jpn J. Clin. Oncol. 28: 323-328.

Oda Y, Ohishi Y, Saito T, Hinoshita E, et al. (2003) Nuclear expression of Y-box-binding protein-1 correlates with P-glycoprotein and topoisomerase II alpha expression, and with poor prognosis in synovial sarcoma. J. Pathol. 199: 251-258.

Rigato I, Cravatari M, Avellini C, Ponte E, et al. (2007). Drug-induced acute cholestatic liver damage in a patient with mutation of UGT1A1. Nat. Clin. Pract. Gastroenterol. Hepatol. 4: 403-408.

Schindelin H, Jiang W, Inouye M and Heinemann U (1994). Crystal structure of CspA, the major cold shock protein of Escherichia coli. Proc. Natl. Acad. Sci. U. S. A. 91: 5119-5123.

Shibao K, Takano H, Nakayama Y, Okazaki K, et al. (1999). Enhanced coexpression of YB-1 and DNA topoisomerase II alpha genes in human colorectal carcinomas. Int. J. Cancer. 83: 732-737

Shiota M, Itsumi M, Yokomizo A, Takeuchi A, et al. (2014), Targeting ribosomal S6 kinases/Y-box binding protein-1 signaling improves cellular sensitivity to taxane in prostate cancer. Prostate 74: 829-838.

Sommerville J and Ladomery M (1996). Transcription and masking of mRNA in germ cells: involvement of Y-box proteins. Chromosoma 104: 469-478.

Stratford AL, Habibi G, Astanehe A, Jiang H, et al. (2007) Epidermal growth factor receptor (EGFR) is transcriptionally induced by the Y-box binding protein-1 (YB-1) and can be inhibited with Iressa in basal-like breast cancer, providing a potential target for therapy. Breast Cancer Res. 9: R61.

Tafuri SR, Familari M and Wolffe AP (1993). A mouse Y box protein, MSY1, is associated with paternal mRNA in spermatocytes. J. Biol. Chem. 268: 12213-12220.

Tamura K, Peterson D, Peterson N, Stecher G, et al. (2011). MEGA5: Molecular evolutionary genetics analysis using maximum likelihood, evolutionary distance, and maximum parsimony methods. Mol. Biol. Evol. 28: 2731-2739.

Thieringer HA, Singh K, Trivedi H and Inouye M (1997). Identification and developmental characterization of a novel Y-box protein from Drosophila melanogaster. Nucleic Acids Res. 25: 4764-4770.

Wolffe AP (1994). Structural and functional properties of the evolutionarily ancient Y-box family of nucleic acid binding proteins. Bioessays 16: 245-251.

Wolffe AP, Tafuri S, Ranjan M and Familari M (1992). The Y-box factors: a family of nucleic acid binding proteins conserved from Escherichia coli to man. New Biol. 4: 290-298.

Yamanaka K, Fang L and Inouye M (1998). The CspA family in Escherichia coli: multiple gene duplication for stress adaptation. Mol. Microbiol. 27: 247-255.

Yu J, Hecht NB and Schultz RM (2001). Expression of MSY2 in mouse oocytes and preimplantation embryos. Biol. Reprod. 65: 1260-1270.

Yu J, Deng M, Medvedev S, Yang J, et al. (2004). Transgenic RNAi-mediated reduction of MSY2 in mouse oocytes results in reduced fertility. Dev. Biol. 268: 195-206. 